\title{
Breed-specific patterns of hepatic gluconeogenesis and glucocorticoid action in pigs
}

\author{
Xiaojing Yang ${ }^{1 *}$, Rui Liu*, Elke Albrecht ${ }^{2}$, Xia Dong', Steffen Maak² and Ruqian Zhao' \\ ${ }^{1}$ Key Laboratory of Animal Physiology and Biochemistry, Nanjing Agricultural University, Nanjing, P.R. China, ${ }^{2}$ Research \\ Unit Muscle Biology and Growth, Leibniz Institute for Farm Animal Biology (FBN), Dummerstorf, Germany
}

\begin{abstract}
In the present study, Erhualian and Pietrain pigs were employed to investigate the breedspecific patterns of hepatic gluconeogenesis by detecting the related enzyme mRNA expression, and to analyse the relationship with the hepatic glucocorticoid receptors and $11 \beta$-hydroxysteroid dehydrogenase type 1 (11 $\beta$-HSD1) expression. Furthermore, hepatic DNA methyltransferase 1 (DNMT1) expression was determined to detect DNA methyltransferase state difference between the two breeds. The results demonstrated that the Erhualian pigs exhibited significantly lower plasma lactate acid concentration, but higher liver lactate acid content than the Pietrain pigs. A significantly higher expression of pyruvate carboxylase $(\mathrm{PC})$, fructose-1, 6-bisphosphatase (FBP) and the mitochondria phosphoenolpyruvate carboxykinase ( $P$ CK2) mRNA were observed in Erhualian pigs. The Erhualian pigs demonstrated a significantly higher expression of glucocorticoid receptor and 11ß-HSD1 mRNA than the Pietrain pigs, though there was no difference in the hepatic cortisol content between the two breeds. The hepatic DNMT1 mRNA expression in the Erhualian pigs was significantly lower, and the DNMT1 protein content in Erhualian pigs tended to be decreased compared with Pietrain pigs $(P=0.066)$. The results suggest that the Erhualian pigs demonstrated higher hepatic gluconeogenesis capacity in comparison to the Pietrain pigs. The up-regulation of hepatic glucocorticoid receptor and 11ß-HSD1 expression may be involved in the enhanced hepatic gluconeogenesis in Erhualian pigs. Moreover, the down-regulation of DNMT1 in Erhualian pigs implies possible involvement of DNA methylation in a breed-specific pattern of hepatic gluconeogenesis.
\end{abstract}

Keywords: pigs, gluconeogenesis, liver, glucocorticoid receptor, DNA methyltransferases 1

\section{Introduction}

Gluconeogenesis, a key metabolic process, involves the formation of glucose and glycogen from non-glucose precursors. Gluconeogenesis provides the glucose required during prolonged fasting and stress, and the process primarily occurs in the liver. Most studies on gluconeogenesis in pigs focused on the newborn piglets (Robinson et al. 1981, Pégorier et al. 1984, Lepine et al. 1993). In fact during pig growth and slaughter process, pigs are exposed to considerable stress. One of stress consequences is the increasing blood lactate acid resulting

*Both authors contributed equally to this work. 
in detrimental effects on skeletal muscle (Von Borell 2000, Manteuffel et al. 2002, Hambrecht et al. 2004). While gluconeogenesis provides a solution to reduce the blood lactate acid concentration.

Glucocorticoids are essential for diverse physiological functions, including cell differentiation, carbohydrate, protein and lipid metabolism, and stress responses. In vitro studies demonstrated that dexamethasone significantly elevated the rates of hepatic gluconeogenesis (Allan et al. 1984). Additionally, the absence of glucocorticoid receptors in hepatocytes limits the development of hyperglycaemia in mice with streptozotocin-induced diabetes mellitus, which is likely due to impaired induction of gluconeogenesis (Opherk et al. 2004).

Erhualian pigs are a typical indigenous Chinese breed, belonging to the same family as the Meishan pigs, which are characterised by high fertility and stress resistance (Li et al. 2008a). In contrast, Pietrain pigs are known for their fast lean mass deposition, but higher stress sensitivity. Furthermore the big difference of plasma cortisol content was confirmed in previous studies between the two breeds (Désautés et al. 1999, Li et al. 2008b). The question arises whether a big difference in the gluconeogenesis capacity exists between the two breeds and whether the different gluconeogenesis capacity is related to the basal plasma glucocorticoid level.

Recent studies have shown that gene expression is largely regulated by epigenetic modifications of DNA and histones in chromatin. Among these epigenetic modifications, DNA methylation plays an important role in transcriptional regulation, and it is essential for the development of mammals (Jones \& Takai 2001). In general, DNA methylation is associated with gene silencing, and it is controlled by the DNA methyltransferase (DNMT) family (Szyf 2005).

Therefore, in the present study Erhualian and Pietrain pigs were employed to investigate the breed specific gluconeogenesis pattern by detecting the related enzymes mRNA expression in liver, and to analyse the relationship with the hepatic glucocorticoid receptor and $11 \beta$-hydroxysteroid dehydrogenase type 1 (11ß-HSD1) expression. Additionally, liver DNMT1 expression was measured to show the difference of the DNA methylation state between the two breeds.

\section{Materials and methods}

\section{Animals and sample collection}

Castrated male Erhualian and Pietrain ( $n=6$ ) piglets, weighing $20 \mathrm{~kg}$ in average, were randomly selected from a pig breeding farm in Wuxi, Jiangsu Province, China. The Erhualian pigs were 50-60 days of age and the Pietrain pigs were 30-40 days of age. The piglets were fed twice daily at 06.00 and 17.30 and were allowed free access to water. The piglets were sacrificed via an intravenous injection with an overdose of $3 \%$ sodium pentobarbitone. Blood samples were collected to heparinized tubes and immediately placed on ice. Plasma was separated by centrifugation at $1300 \times \mathrm{g}$ at $4{ }^{\circ} \mathrm{C}$ for $15 \mathrm{~min}$. Plasma samples were stored at $-20^{\circ} \mathrm{C}$ until assay. Small portions of liver were excised, immediately frozen in liquid $\mathrm{N}_{2}$ and then stored at $-80^{\circ} \mathrm{C}$ until further analysis. The animal handling and sampling procedures were performed following the regional Animal Ethics Committee guidelines. 


\section{Lactic acid and glucose content}

Lactic acid concentrations were measured using a commercial lactic acid kit (Nanjing Jiancheng Bioengineering Institute, Nanjing, China) and a UV-visible spectrophotometer Type-752 (Shanghai Jinghua Technology Instrument Ltd. Co., Shanghai, China) at $530 \mathrm{~nm}$ according to the manufacturer's instructions. Glucose content was measured using a commercial glucose kit (Nanjing Jiancheng Bioengineering Institute, Nanjing, China) according to the manufacturer's instructions.

Frozen liver sample $(100 \mathrm{mg})$ was homogenized in $1 \mathrm{~mL}$ of cold $\mathrm{HCLO}_{4}(0.5 \mathrm{mmol} / \mathrm{L})$. The homogenates were centrifuged at $15000 \times \mathrm{g}$ for $20 \mathrm{~min}$ to obtain clear lysates after $10 \mathrm{~min}$ standing. The $3 \mathrm{mmol} / \mathrm{L} \mathrm{K}_{2} \mathrm{CO}_{3}$ was add into the supernatant equal mol to $\mathrm{HCLO}_{4}$. After keeping it for $2 \mathrm{~h}$ in $0^{\circ} \mathrm{C}$, it was centrifuged at $15000 \times \mathrm{g}$ for $10 \mathrm{~min}$ to obtain the supernatant. Commercial Bradford assay kit (Nanjing Jiancheng Bioengineer Institute, Nanjing, China) was used to determine the total protein concentration. Lactic acid and glucose content were determined per mg total protein.

\section{Radioimmunoassay for cortisol content}

Cortisol concentrations were measured using commercial multispecies radioimmunoassay (RIA) kits purchased from the Beijing North Institute of Biotechnology (Beijing, China) according to the manufacturer's instructions. The RIA detection limit was $2 \mathrm{ng} / \mathrm{mL}$. The intraand interassay coefficients of variations were $7.6 \%$ and $8.7 \%$, respectively.

\section{RNA extraction and mRNA quantification}

Total RNA was extracted from homogenized liver tissues using a TRIzol Total RNA Kit (Invitrogen Life Technologies, Carlsbad, CA, USA) and was subsequently purified with the RNase-Free DNase Set (Promega, Fitchburg, WI, USA), according to the manufacturer's instructions. The total RNA concentration was then quantified by measuring the absorbance at $260 \mathrm{~nm}$ with a photometer (Eppendorf AG, Hamburg, Germany). The $260 / 280 \mathrm{~nm}$ absorption ratios of all the preparations were between 1.9 and 2.1. Two $\mu \mathrm{g}$ of total RNA were reversely transcribed in a final volume of $25 \mu \mathrm{L}$ with M-MLV reverse transcriptase (Promega, Fitchburg, WI, USA) and random hexamer primers (SunShine, China) in a Thermal Cycler PTC0200 (Bio-Rad, Hercules, (A, USA).

Real-time PCR was performed in a Mx3000P machine (Agilent Technologies, Inc., Santa Clara, CA, USA) with specific primers. All of the primers were designed and synthesized by Takara Biotechnology (China). All samples were normalized with the housekeeping gene $18 \mathrm{~S}$ rRNA. The sequences of the PCR primers are shown in Table 1. Different controls were used to monitor genomic and environmental DNA contamination during reverse transcription (RT) and PCR. Samples were pooled by mixing equal quantities of CDNA from all samples to optimize the PCR conditions and generate standard curves for each target gene. The specificities of the reactions were checked using melting curve analyses for each gene.

The $2^{-\Delta \Delta C t}$ method (Livak \& Schmittgen 2001) was used to analyse the real-time PCR data. The average value of the Pietrain pigs was set as 1 . 
Table 1

Primer sequences of the target genes

\begin{tabular}{|c|c|c|c|}
\hline Target genes & GenBank accession & PCR products (bp) & Primer sequences \\
\hline PC & AY225510 & 130 & $\begin{array}{l}\text { F: 5'-CCG CAA GAT GGG AGA CA-3' } \\
\text { R: 5'-GAA GCC GTA GGT GTT GGA3-3' }\end{array}$ \\
\hline PCK1 & AY855075 & 123 & $\begin{array}{l}\text { F: } 5^{\prime}-C G G \text { GAT TTC GTG GAG A-3' } \\
\text { R: 5'-CCT CTT GAT GAC ACC CTC T-3' }\end{array}$ \\
\hline PCK2 & AY855076 & 323 & $\begin{array}{l}\text { F: } 5^{\prime}-\text { CAT TCA GCA TGG GTC C }-3^{\prime} \\
\text { R: } 5^{\prime} \text {-GAT GCG AAG GGC AAA G-3' }\end{array}$ \\
\hline FBP & NM_213979 & 106 & $\begin{array}{l}\text { F: } 5^{\prime}-A C C \text { CTA ACC CGC TTC GTC-3' } \\
\text { R: 5'-CGG TGG AGA TGG CTT TGA-3' }\end{array}$ \\
\hline G6P & NM_213979 & 264 & $\begin{array}{l}\text { F: } 5^{\prime}-\text { CAA TCA GTG CCA AGT C-3' } \\
\text { R: } 5^{\prime}-\text { GCT ACC CAG AGG AGT T-3' }\end{array}$ \\
\hline GR & NM_001008481 & 382 & $\begin{array}{l}\text { F: } 5^{\prime}-\text { ACG CTA AGT TGT TTA TCT CG-3' } \\
\text { R: } 5^{\prime} \text {-CCC ATC ACT TTA GTT TCG-3' }\end{array}$ \\
\hline $11 \beta-H S D 1$ & AY225510 & 115 & $\begin{array}{l}\text { F: } 5^{\prime}-C C A \text { TGC TGA AGC AGA GCA AC-3' } \\
\text { R: } 5^{\prime}-A A G \text { AAC CCG TCC AGA GCA AA-3' }\end{array}$ \\
\hline DNMT1 & DQ060156 & 133 & $\begin{array}{l}\text { F: 5'-GCG GGA CCT ACC AAA CAT-3' } \\
\text { R: 5'-TTC CAC GCA GGA GCA GAC-3' }\end{array}$ \\
\hline $18 \mathrm{~S}$ & AY265350 & 122 & $\begin{array}{l}\text { F: } 5^{\prime}-C C C \text { ACG GAA TCG AGA AAG AG-3' } \\
\text { R: } 5^{\prime}-{ }^{\prime} \text { TTG ACG GAA GGG CAC CA-3' }\end{array}$ \\
\hline
\end{tabular}

GR: glucocorticoid receptor

\section{Determination of protein expression}

Frozen liver sample $(100 \mathrm{mg})$ was homogenized in $1 \mathrm{~mL}$ of cold homogenization buffer (500 mM Tris-HCl pH 6.8, $10 \%$ [v/v] glycerol, $10 \%$ [w/v] sodium dodecyl sulfate [SDS], $10 \%$ [v/v] 2-mercaptoethanol). The homogenates were centrifuged at $5000 \times \mathrm{g}$ for $20 \mathrm{~min}$ to obtain clear lysates. Protein concentrations were measured using Bradford assays. Protein extract $(30 \mu \mathrm{g})$ was mixed with loading buffer and denatured by boiling for $5 \mathrm{~min}$ before being loaded on a $12 \%$ SDS-PAGE gel. Following electrophoresis, proteins were transferred to a nitrocellulose membrane and then blocked with a solution of $5 \%$ fat-free milk in TweenTris-buffer saline (TTBS) for $2 \mathrm{~h}$ at room temperature. After repeated washing with TTBS, the membrane was incubated with a monoclonal antibody to DNMT1 (Imgenex Corp., San Diego, CA, USA; dilution 1:2000) and a monoclonal antibody to $\beta$-actin (Abcam, Cambridge, UK; dilution 1:2000) for $2 \mathrm{~h}$ at room temperature. Then the membrane was washed five times ( $15 \mathrm{~min}$ for the first wash and $5 \mathrm{~min}$ wash thereafter) to remove unbound antibodies. Anti-rabbit IgG conjugated with horseradish peroxidase (Jingmei Biological Engineering Company, Wuhan, China; 1:5000 dilution) was used as the secondary antibody. Finally, the membrane was washed five times (as indicated above) and the specific signals were detected by chemiluminescence using the LumiGlo substrate (Pierce Super Signal West Pico Trial Kit, Thermo Fisher Scientific Inc., Waltham, MA, USA). Enhanced chemiluminescence signals were recorded on X-ray film. The enhanced chemiluminescence signals were scanned and analysed with a Kodak 1D Electrophoresis Documentation and Analysis System 120 (Kodak Photo Film Co. Ltd., Rochester, NY, USA). 


\section{Statistic analysis}

All data are presented as the mean \pm SEM. Statistical differences were tested using $\mathrm{t}$-test for independent samples with SPSS13.0 for Windows (SPSS Inc., Chicago, IL, USA). The mRNA and protein levels were expressed as the fold change relative to the mean value of the Pietrain pigs. A $P$-value $<0.05$ was considered significant.

\section{Results}

Differences of lactate acid and glucose levels in plasma and liver between the Erhualian and Pietrain pigs

As shown in Table 2, the Erhualian pigs exhibited significantly lower plasma lactate acid concentration but higher hepatic lactate acid content than the Pietrain pigs $(P<0.05)$. The glucose content in plasma and liver were not significantly different between the two pig breeds.

Table 2

Lactate acid contents in plasma and liver of Erhualian and Pietrain pigs

\begin{tabular}{lcc}
\hline Indices & Erhualian & \multicolumn{1}{c}{ Pietrain } \\
\hline Plasma glucose, $\mathrm{mmol} / \mathrm{L}$ & $4.16 \pm 0.10$ & $4.33 \pm 0.12$ \\
Hepatic glucose, $\mathrm{mmol} / \mathrm{g}$ protein & $27.72 \pm 3.66$ & $32.51 \pm 3.80$ \\
Plasma lactate acid, $\mathrm{mmol} / \mathrm{L}$ & $1.52 \pm 0.07^{*}$ & $1.81 \pm 0.06$ \\
Hepatic lactate acid, $\mathrm{mmol} / \mathrm{g}$ protein & $0.45 \pm 0.02^{* *}$ & $0.39 \pm 0.01$ \\
\hline
\end{tabular}

${ }^{*} P<0.05,{ }^{*} P<0.01$, represent significant differences between the two breeds

Differences of hepatic gluconeogenesis key enzymes expression between the two breeds

The Erhualian pigs exhibited a significantly higher expression of pyruvate carboxylase (PC) mRNA $(P<0.05)$ than the Pietrain pigs (Figure 1a). No difference was observed in cytosolic phosphoenolpyruvate carboxykinase (PCK1) mRNA expression, whereas mitochondrial phosphoenolpyruvate carboxykinase (PCK2) mRNA expression was higher in the Erhualian pigs $(P<0.05)$ than in the Pietrain pigs (Figure 1b, 1c). Fructose-1, 6-bisphosphatase (FBP) mRNA was significantly up-regulated in Erhualian pigs $(P<0.05)$ compared with the Pietrain pigs (Figure 1d). There was no difference in glucose-6-phosphatase (G6P) mRNA between the two pig breeds (Figure 1e).

Differences of cortisol content and the glucocorticoid receptor, $11 \beta-H S D 1$ expression between the two breeds

The cortisol concentrations in serum of Erhualian and Pietrain were $290.6 \pm 26.0 \mathrm{ng} / \mathrm{ml}$ and $156.1 \pm 30.1 \mathrm{ng} / \mathrm{ml}$, and the cortisol contents in liver were $51.3 \pm 7.8 \mathrm{ng} / \mathrm{ml}$ and $47.1 \pm 4.6 \mathrm{ng} / \mathrm{ml}$, respectively. There was a significant difference in serum cortisol content, while no difference was observed in hepatic cortisol concentration between the two breeds.

The Erhualian pigs demonstrated significantly higher hepatic expression of glucocorticoid receptor and 11 $\beta-$ HSD1 mRNA $(P<0.05)$ than the Pietrain pigs (Figure 2). 
a)
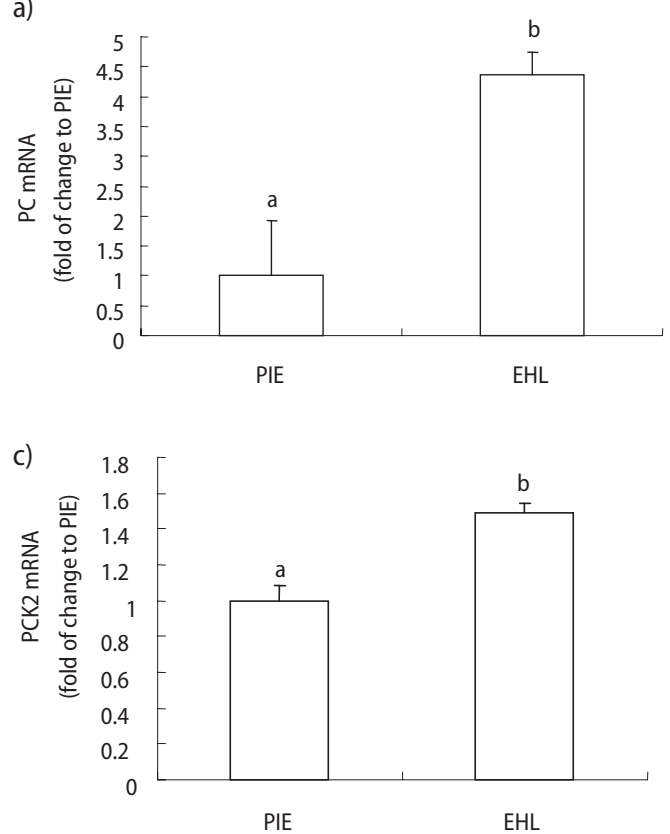

e)

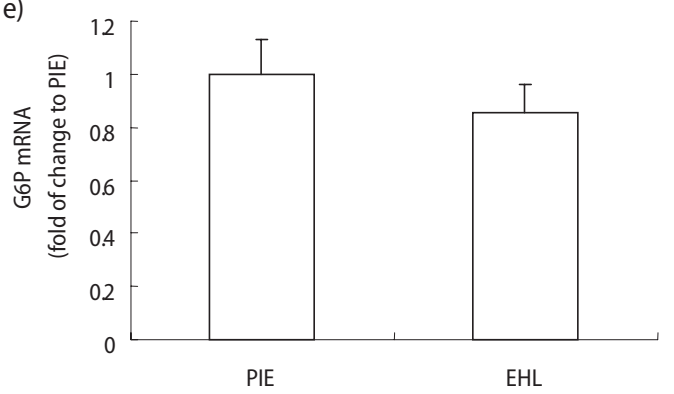

a)

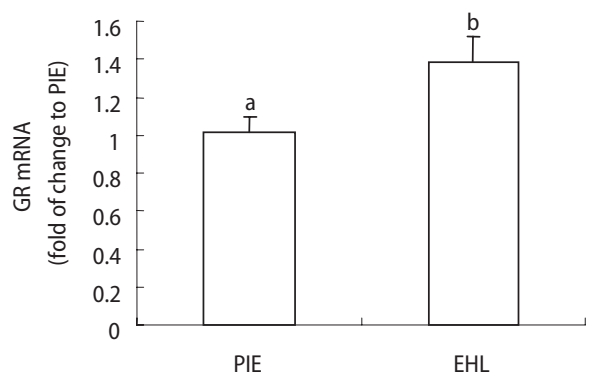

b) $\quad 1.6$

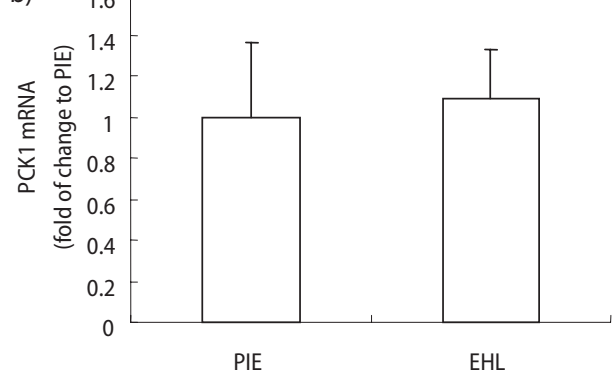

d)

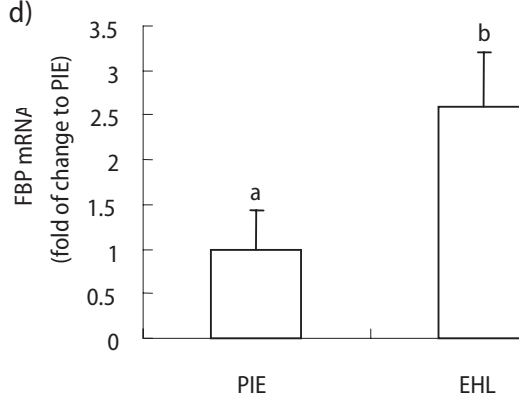

a) PC, b) PCK1, c) PCK2, d) FBP, e) G6P. Mean values without a common superscript differ significantly between breeds $(P<0.05, \mathrm{n}=6)$.

Figure 1

mRNA expression of key enzymes for hepatic gluconeogenesis in Erhualian and Pietrain pigs

b)

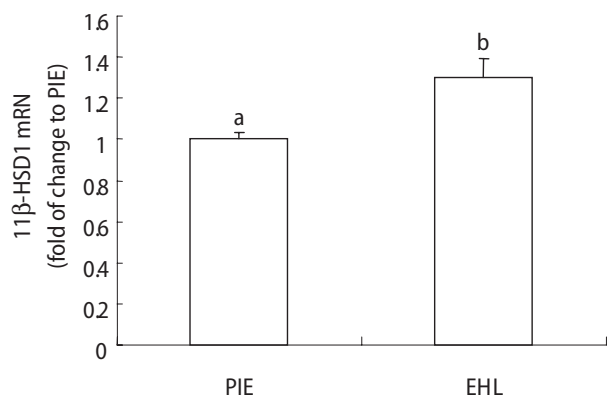

a) glucocorticoid receptor, b) 11 $\beta$-HSD1. Mean values without a common superscript differ significantly between breeds $(P<0.05, \mathrm{n}=6)$.

Figure 2

Hepatic glucocorticoid receptor and 11ß-HSD1 mRNA expression in Erhualian and Pietrain pigs 


\section{Differences of the hepatic DNMT1 expression between the two breeds}

The hepatic DNMT1 mRNA expression (Figure 3a) in the Erhualian pigs was significantly lower than in the Pietrain pigs $(P<0.05)$. The hepatic DNMT1 protein content (Figure $3 b)$ in the Erhualian pigs tended to be lower than in the Pietrain pigs $(P=0.066)$.

a)

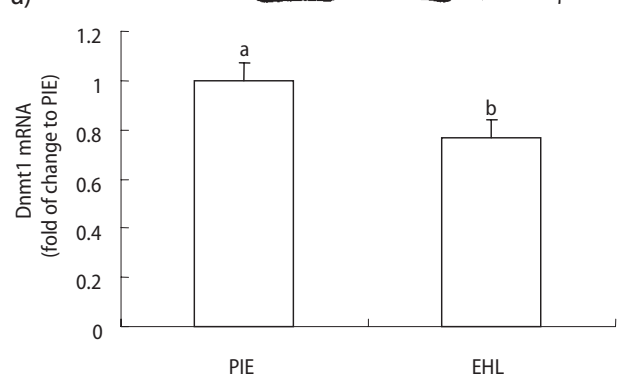

b)

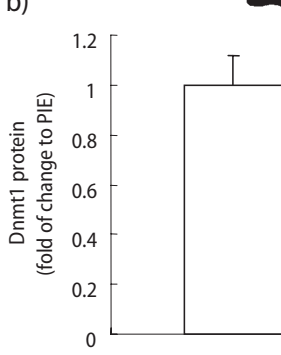

PIE
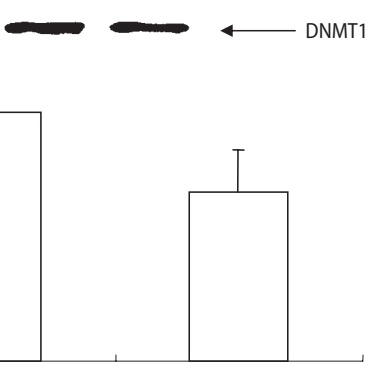

EHL

a) mRNA expression, b) top: protein expression, immunoreactive bands; bottom: statistical results. Mean values without a common superscript differ significantly between breeds $(P<0.05, n=6)$.

Figure 3

Expression of liver DNMT1 mRNA and protein in Erhualian and Pietrain pigs.

\section{Discussion}

Most of earlier studies on the gluconeogenesis in pigs focused at the newborn stage (Robinson et al. 1981, Pégorier et al. 1984, Lepine et al. 1993), yet in the present study we first demonstrated the breed difference of hepatic gluconeogenesis between the pure Chinese pigs and Pietrain pigs after weaning. In previously studies it has been confirmed that there is different stress response between the two breeds (Désautés et al. 1999, Li et al. 2008a). The present study implied the different capacity of gluconeogenesis may be partly responsible for the distinct stress reaction.

The mutation of the type 1 ryanodine receptor gene was detected in the present study and the results showed that all the Pietrain pigs were homozygous halothane-positive $\left(\mathrm{Hal}{ }^{\mathrm{nn}}\right)$ pigs, whereas Erhualian pigs are homozygous halothane-negative $(\mathrm{HalNN})$ pigs; and it has been confirmed that $\mathrm{Hal}^{\text {nn }}$ pigs showed a drastic reduction in the level of glycogen to cope with stress (Scholz et al. 2003). Then amount of lactate is generated in muscle tissue. One of important way to removal of excess lactate is by gluconeogenesis in the liver (Brooks 2009). The present study showed the lactate acid concentration in plasma and liver showed distinct pattern between two breeds. Plasma lactate acid concentration in the Erhualian pigs was significantly lower than in Pietrain pigs, whereas the reverse condition was observed for the hepatic lactate acid content. The higher plasma lactate acid is consistent with the characteristic of stress susceptible in Pietrain pigs. The different lactate acid metabolic pattern between the two breeds has never been reported before as far as we know. It indicates that Erhualian pigs have a stronger ability to transport the lactate acid to the liver for metabolism and to decrease the hurt of lactate acid to the body. The glucose content in plasma and liver showed no significant difference between the two breeds. 
In the liver, gluconeogenesis can be controlled by a number of key enzymes including PC, PCK, FBP, and G6P (Pilkis \& Claus 1991). In mammals, PC plays a crucial role in gluconeogenesis by catalysing the ATP-dependent carboxylation of pyruvate to oxaloacetate (Jitrapakdee \& Wallace 1999). In the present study, the mRNA expression of PC in Erhualian pigs was significantly higher than in Pietrain pigs. The next rate-limiting step in gluconeogenesis is the conversion of oxaloacetate to phosphoenolpyruvate (PEP) by PCK, which is considered the major regulative step in gluconeogenesis (Hanson \& Garber 1972). Previous research has demonstrated that there are cytosolic and mitochondrial forms of the PCK enzyme: PCK1 and PCK2 (Cornell et al. 1986). The intracellular distribution of these isoenzymes varies widely with species and organs (Suzuki et al. 2004). In pigs, it has been reported that starvation increased PCK1 activity without changing the mitochondrial activity (Hamada \& Matsumoto 1984). Our results demonstrated that in PCK2 expression existed significant breed differences, while there were no significant differences in PCK1 expression. FBP also plays an important role in gluconeogenesis (Tashima et al. 1983), and the FBP mRNA expression in the Erhualian pigs was significantly higher than in the Pietrain pigs as expected. G6P was reported to contribute significantly to the glucose supply during long-term fasting (Mithieux 1996). However, in the present study, there was no significant difference in G6P expression between the two breeds. Taken together, the higher expression of PC, FBP, and PCK2 genes may contribute to the higher hepatic gluconeogenesis capacity in the Erhualian pigs in comparison to the Pietrain pigs. Therefore, the higher capacity to utilize blood lactate acid for gluconeogenesis may be one reason for higher stress resistance of Erhualian than Pietrain pigs.

In previous studies, dexamethasone treatment was reported to affect gluconeogenesis directly by increasing PC, PCK and FBP mRNA expression (Allan et al. 1984, Tashima et al. 1984, Hammon et al. 2005). Although there was large difference in the blood cortisol levels between the two breeds, there was no significant difference in the hepatic cortisol concentration in the present study. The glucocorticoid receptor mediates glucocorticoid action (Payne \& Adcock 2001). Opherk (2004) reported that glucocorticoid receptor play the essential role in liver glucose metabolism for the mice showed hypoglycaemia after prolonged starvation due to reduced expression of genes involved in gluconeogenesis. In the present study glucocorticoid receptor mRNA expression was shown to be significantly higher in Erhualian pigs than in Pietrain pigs. We selected PC as an example to analyse the relationship with glucocorticoid receptor, and the data showed that glucocorticoid receptor mRNA expression was correlated with the $P C$ mRNA expression $(r=0.57, P<0.05)$. $11 \beta-H S D 1$, which converts inert 11-dehydrocortisone to active cortisol, influences intracellular glucocorticoid concentrations (Altuna et al. 2006). It has been reported that $11 \beta$-HSD1 knockout mice showed attenuated activation of the key hepatic gluconeogenesis enzymes (Kotelevtsev et al. 1997). In the present study, 11 $\beta$-HSD1 mRNA expression was significantly higher in Erhualian pigs than in Pietrain pigs. It can be inferred that it is hepatic glucocorticoid receptor and 11ß-HSD1, but not hepatic cortisol content, mediated the breed difference of glucocorticoid action in the liver.

DNA methylation is supposed to play a crucial role in repressing gene expression possibly by blocking the promoters at which activating transcription factors bind (Wang et al. 2007, Collas 2009). DNMTs catalyse the addition of methyl groups, which are derived from the methyl donor S-adenosyl methionine, onto DNA strands (Rice et al. 2007). Based on structural 
differences in their regulatory N-terminal domains, three distinct families of DNMTs have been classified, namely DNMT1, DNMT2 and DNMT3 (Okano et al. 1998, Snykers et al. 2009). Among them, DNMT1 is the major DNA methyltransferase in the liver (Saito et al. 2003).

Both in vivo and in vitro studies show that maternal behaviour increases glucocorticoid receptor expression in offspring by increasing DNA demethylation (Weaver 2007). In maternal protein-restriction experiments, glucocorticoid receptor gene methylation was $22.8 \%$ lower $(P<0.05)$ in restricted protein pups (Lillycrop et al. 2005) and DNMT1 expression was $17 \%$ lower $(P<0.05)$ than in control pups (Lillycrop et al. 2007). In the present study, the DNMT1 mRNA expression in liver of Erhualian pigs was significantly lower than in Pietrain pigs. Furthermore, the DNMT1 protein content in Erhualian pigs tended to be lower in Pietrain pigs. These data indicate possible involvement of DNA methylation in the breed-specific pattern of hepatic gluconeogenesis. Clearly, further studies are necessary to clarify the specific genes and methylation status, and give the new insights into the underlying mechanisms of the breed gluconeogenesis difference.

\section{Acknowledgement}

This work was supported by the Special Fund for Agro-scientific Research in the Public Interest (201003011), the National Natural Science Foundation of China (30700583), and A Project Funded by the Priority Academic Program Development of Jiangsu Higher Education Institutions.

\section{References}

Allan EH, Titheradge MA (1984) Effect of treatment of rats with dexamethasone in vivo on gluconeogenesis and metabolite compartmentation in subsequently isolated hepatocytes. Biochem J 219, 117-123

Altuna ME, Lelli SM, San Martín de Viale LC, Damasco MC (2006) Effect of stress on hepatic 11betahydroxysteroid dehydrogenase activity and its influence on carbohydrate metabolism. Can J Physiol Pharmacol 84, 977-984

Brooks GA (2009) Cell-cell and intracellular lactate shuttles. J Physiol 587, 5591-5600

Collas P (2009) Epigenetic states in stem cells. Biochem Biophys Acta 1790, 900-905

Cornell NW, Schramm VL, Kerich MJ, Emig FA (1986) Subcellular location of phosphoenolpyruvate carboxykinase in hepatocytes from fed and starved rats. J Nutr 116, 1101-1108

Désautés C, Sarrieau A, Caritez JC, Mormède $P(1999)$ Behavior and pituitary-adrenal function in large white and Meishan pigs. Domest Anim Endocrin 16, 193-205

Hamada T, Matsumoto M (1984) Effects of nutrition and ontogeny on liver cytosolic and mitochondrial phosphoenolpyruvate carboxykinase activity of the rat, hamster, guinea-pig, pig, kid, calf and chick. Comp Biochem Physiol B 77, 547-550

Hambrecht E, Eissen JJ, Nooijent RIJ, Ducro BJ, Smits CHM, den Hartog LA, Verstegen MW (2004) Preslaughter stress and muscle energy largely determine pork quality at two commercial processing plants. J Anim Sci $82,1401-1409$

Hammon HM, Philipona C, Zbinden Y, Blum JW, Donkin SS (2005) Effects of dexamethasone and growth hormone treatment on hepatic gluconeogenic enzymes in calves. J Dairy Sci 88, 2107-2116

Hanson RW, Garber AJ (1972) Phosphoenolpyruvate carboxykinase. I. Its role in gluconeogenesis. Am J Clin Nutr 25, 1010-1021

Jones PA, Takai D (2001) The role of DNA methylation in mammalian epigenetics. Science 293, 1068-1070 
Jitrapakdee S, Wallace JC (1999) Structure, function and regulation of pyruvate carboxylase. Biochem J 340, 1-6

Kotelevtsev Y, Holmes MC, Burchell A, Houston PM, Schmoll D, Jamieson P, Best R, Brown R, Edwards CRW, Seckl JR, Mullins JJ (1997) 11beta-hydroxysteroid dehydrogenase type 1 knockout mice show attenuated glucocorticoid-inducible responses and resist hyperglycemia on obesity or stress. Proc Natl Acad Sci USA 94, 14924-14929

Lepine AJ, Watford M, Boyd RD, Ross DA, Whitehead DM (1993) Relationship between hepatic fatty acid oxidation and gluconeogenesis in the fasting neonatal pig. Br J Nutr 70, 81-91

Li LA, Xia D, Bao ED, Wei S, Xiao JS, Bao JW, Chen WH, Chen J, Hartung J, Zhao RQ (2008a): Erhualian and Pietrain pigs exhibit distinct behavioral, endocrine and biochemical responses during transport. Livest Sci $113,169-177$

Li LA, Xia D, Wei S, Hartung J, Zhao RQ (2008b) Characterization of adrenal ACTH signaling pathway and steroidogenic enzymes in Erhualian and Pietrain pigs with different plasma cortisol levels. Steroids 73, 806-814

Lillycrop KA, Phillips ES, Jackson AA, Hanson MA, Burdge GC (2005) Dietary protein restriction of pregnant rats induces and folic acid supplementation prevents epigenetic modification of hepatic gene expression in the offspring. J Nutr 135, 1382-1386

Lillycrop KA, Slater-Jefferies JL, Hanson MA, Godfrey KM, Jackson AA, Burdge GC (2007) Induction of altered epigenetic regulation of the hepatic glucocorticoid receptor in the offspring of rats fed a protein-restricted diet during pregnancy suggests that reduced DNA methyltransferase-1 expression is involved in impaired DNA methylation and changes in histone modifications. Br J Nutr 97, 1064-1073

Livak KJ, Schmittgen TD (2001) Analysis of relative gene expression data using real-time quantitative PCR and the 2(-Delta Delta C(T)) method. Methods 25, 402-408

Manteuffel G (2002) Central nervous regularization of the hypothalamus- pituitary-adrenal axis and its impact on fertility, immunity, metabolism and animal welfare - A review. Arch Tierz 45, 575-595

Mithieux G (1996) Role of glucokinase and glucose- 6 phosphatase in the nutritional regulation of endogenous glucose production. Reprod Nutr Dev 36, 357-362

Okano M, Xie S, Li E (1998) Cloning and characterization of a family of novel mammalian DNA (cytosine-5) methyltransferases. Nat Genet 19, 219-220

Opherk C, Tronche F, Kellendonk C, Kohlmüller D, Schulze A, Schmid W, Schütz G (2004) Inactivation of the glucocorticoid receptor in hepatocytes leads to fasting hypoglycemia and ameliorates hyperglycemia in streptozotocin-induced diabetes mellitus. Mol Endocrinol 18, 1346-1353

Payne DN, Adcock IM (2001) Molecular mechanisms of corticosteroid actions. Paediatr Respir Rev 2, 145-150

Pégorier JP, Duée PH, Nunes CS, Peret J, Girard J (1984) Glucose turnover and recycling in unrestrained and unanesthetized 48-h-old fasting or post-absorptive newborn pigs. Br J Nutr 52, 277-287

Pilkis SJ, Claus TH (1991) Hepatic gluconeogenesis/glycolysis: regulation and structure/function relationships of substrate enzymes. Annu Rev Nutr 11, 465-515

Rice KL, Hormaeche I, Licht JD (2007) Epigenetic regulation of normal and malignant hematopoiesis. Oncogene 26, 6697-6714

Robinson JL, Duee PH, Schreiber O, Bois-Joyeux B, Chanez M, Pégorier JP, Peret J (1981) Development of gluconeogenic enzymes in the liver of fasting or suckling newborn pigs. J Dev Physiol 3, 191-201

Saito Y, Kanai Y, Nakagawa T, Sakamoto M, Saito H, Ishii H, Hirohashi S (2003) Increased protein expression of DNA methyltransferase (DNMT) 1 is significantly correlated with the malignant potential and poor prognosis of human hepatocellular carcinomas. Int J Cancer 105, 527-532

Scholz AM, Mitchel AD, Song H, Wang PC (2003) ${ }^{13} \mathrm{C}$ nuclear magnetic resonance spectroscopy - a non-invasive muscle measure in vivo method tons glycogen metabolism in pigs of different genotypes. Arch Tierz 46, 199-211

Snykers S, Henkens T, De Rop ED, Vinken M, Fraczek J, Kock JD, De Prins ED, Geerts A, era Rogiers, Vanhaecke $\mathrm{T}$ (2009) Role of epigenetics in liver-specific gene transcription, hepatocyte differentiation and stem cell reprogrammation. J Hepatol 51, 187-211 
Suzuki M, Yamasaki T, Shinohata R, Hata M, Nakajima H, Kono N (2004) Cloning and reporter analysis of human mitochondrial phosphoenolpyruvate carboxykinase gene promoter. Gene 338, 157-162

Szyf M (2005) DNA methylation and demethylation as targets for anticancer therapy. Biochemistry (Mosc.) 70, 533-549

Tashima Y, Mizunuma H, Kumegawa M (1983) Induction of fructose 1,6-bisphosphatase and glucose 6-phosphatase in fetal mouse liver. Arch Biochem Biophys 220, 379-385

Tashima Y, Mizunuma H, Shima H, Kobayashi R, Hakeda Y, Maeda, N, Kumegawa M (1984) Effect of glucocorticoids on induction of fructose bisphosphatase and glucose-6-phosphatase in fetal mouse liver. J Biochem 96, 1619-1624

von Borell E (2000) Stress and coping in farm animals. Arch Tierz 43 Special Issue, 144-152

Wang GG, Allis CD, Chi P (2007) Chromatin remodeling and cancer. Ppart I: Covalent histone modifications. Trends Mol Med 13, 363-372

Weaver IC (2007) Epigenetic programming by maternal behavior and pharmacological intervention. Nature versus nurture: let's call the whole thing off. Epigenetics 2, 22-28

Received 29 August 2011, accepted 15 November 2011.

Corresponding author:

Ruqian Zhao

email: zhaoruqian@njau.edu.cn

Key Laboratory of Animal Physiology \& Biochemistry, Nanjing Agricultural University, Nanjing 210095, P.R. China 